\title{
Residency and long-distance movements of sevengill sharks (Notorhynchus cepedianus) tagged in San Francisco Bay
}

\author{
James T. Ketchum ${ }^{1}$, Christina J. Slager ${ }^{2}$, Michele L. Buckhorn ${ }^{1}$, Andrew P. Nosal ${ }^{3}$ and A. Peter Klimley ${ }^{1,4^{*}}$
}

\begin{abstract}
Background: Sevengill sharks are common inhabitants of estuaries and coastal areas and particularly abundant in San Francisco Bay (SFB). There is limited knowledge about the level of residency and migratory movements of this species. We describe the degree of residence of sevengill sharks in SFB and nearby locations, using ultrasonic tags and automated listening stations.

Results: Sevengills showed a high degree of residency in SFB, particularly to the Golden Gate (GG) area where they have a strong site preference, both seasonally and inter-annually. Site fidelity was also the highest at the GG. In sharks with deployment times longer than 300 days, we found that $>80 \%$ of visits of all mature males were at GG, $80 \%$ of visits of a single mature female occurred there, $>85 \%$ of visits of most juvenile males, and $>70 \%$ of visits of most juvenile females. At $\mathrm{GG}$, sharks moved into the range of the receiver day and night without a strong preference for a particular time of the day, which implies movements up and down the area day and night. At most other locations within the bay, sharks were present during daytime hours, while at Point Reyes during nighttime hours. Sharks moved into SFB during early spring and summer, and moved out of SFB to Point Reyes during late spring and fall. Three sevengill sharks migrated roughly $800 \mathrm{~km}$ southeastward along the coastline from SFO, one making three trips back and forth between the sites.
\end{abstract}

Conclusions: There was strong evidence of residency of sharks within SFB, and sharks repeatedly returned to the same region of the bay with some sharks making long-distance movements.

\section{Background}

The movements of fish in and around estuaries have been studied extensively for anadromous species (salmons and sturgeons) and to a lesser degree for catadromous species (e.g., eels). For example, the rates of movement have been described in the San Francisco Bay (SFB) Estuary of downstream migrating late-fall run of the anadromous Chinook salmon [1] and steelhead trout [2]. The movement patterns of green sturgeon have also been described within the same estuary [3]. However, little is known about the movements and habitat utilization of elasmobranchs within estuaries (e.g., $[4,5])$. This is because few

\footnotetext{
*Correspondence: apklimley@ucdavis.edu

${ }^{4}$ Present Address: Biotelemetry Consultants, 2870 Eastman Lane, Petaluma, CA 94952, USA

Full list of author information is available at the end of the article
}

sharks such as the bull shark and dasyatid rays tolerate a wide range of salinities (see Chap 4 in [6]).

Sevengill sharks, Notorhynchus cepedianus, inhabit coastal and shelf waters. This species is common within or adjacent to shallow bays in temperate waters. Adult sevengills are common inhabitants of estuaries and bays from southeastern Alaska to the southern end of the Baja Peninsula, and a population exists within the northern Gulf of California [7]. The adults are caught along the continental shelf to a depth of $136 \mathrm{~m}$ [8]. Although adults are commonly captured in Humboldt and San Francisco Bays at certain times of the year, it is not yet known whether they are resident year round and what portion of the population leaves the bays and migrates along the coastal shelf [7]. In this study, we determined the degree 
of residence and extent of movements of sevengill sharks tagged in SFB.

\section{Methods}

\section{Study site}

SFB is large and complex estuary encompassing shallow and deep waters heavily influenced by tidal flow (Fig. 1). For this reason, there are a number of different habitats are present within the bay such as salt marshes, shallow flats, and deep channels. It is the largest estuary of the western coast of North America.

\section{Ultrasonic transmitters and automated receivers}

Twenty coded transmitters (V16-4H, Vemco Ltd., Halifax) were placed on 15 male and five female sevengill sharks, with one coded transmitter equipped with pressure sensor (V16P-4H, Vemco Ltd., Halifax) on a female, during July, August, and September 2008. This tag, $71 \mathrm{~mm}$ long with a diameter of $16 \mathrm{~mm}$, produced a $69-\mathrm{kHz}$ signal with a power output of $158 \mathrm{~dB}$ re $1 \mu \mathrm{Pa}$ at $1 \mathrm{~m}$ and had a rated life of 1350 days (3.7 years). The intervals between the coded pulse bursts varied pseudorandomly from 45 to $90 \mathrm{~s}$ with a nominal delay of $60 \mathrm{~s}$. A coded beacon was detected at a range of $500 \mathrm{~m}$ from an autonomous receiver (VR-02, Vemco Ltd, Halifax) under ideal transmission conditions, i.e., during slack tide when suspended $5 \mathrm{~m}$ below a flat sea surface at the mouth of San Francisco Bay with a depth of $>30 \mathrm{~m}$. The range would be expected to decrease in the presence of higher seas, which produce higher levels of ambient noise, which would reduce the sensitivity of the receiver. Furthermore, the receivers might tilt in the presence of strong currents during outwardly flowing ebb and inwardly flowing flood tags. Due to the highly dynamic nature of this variable,

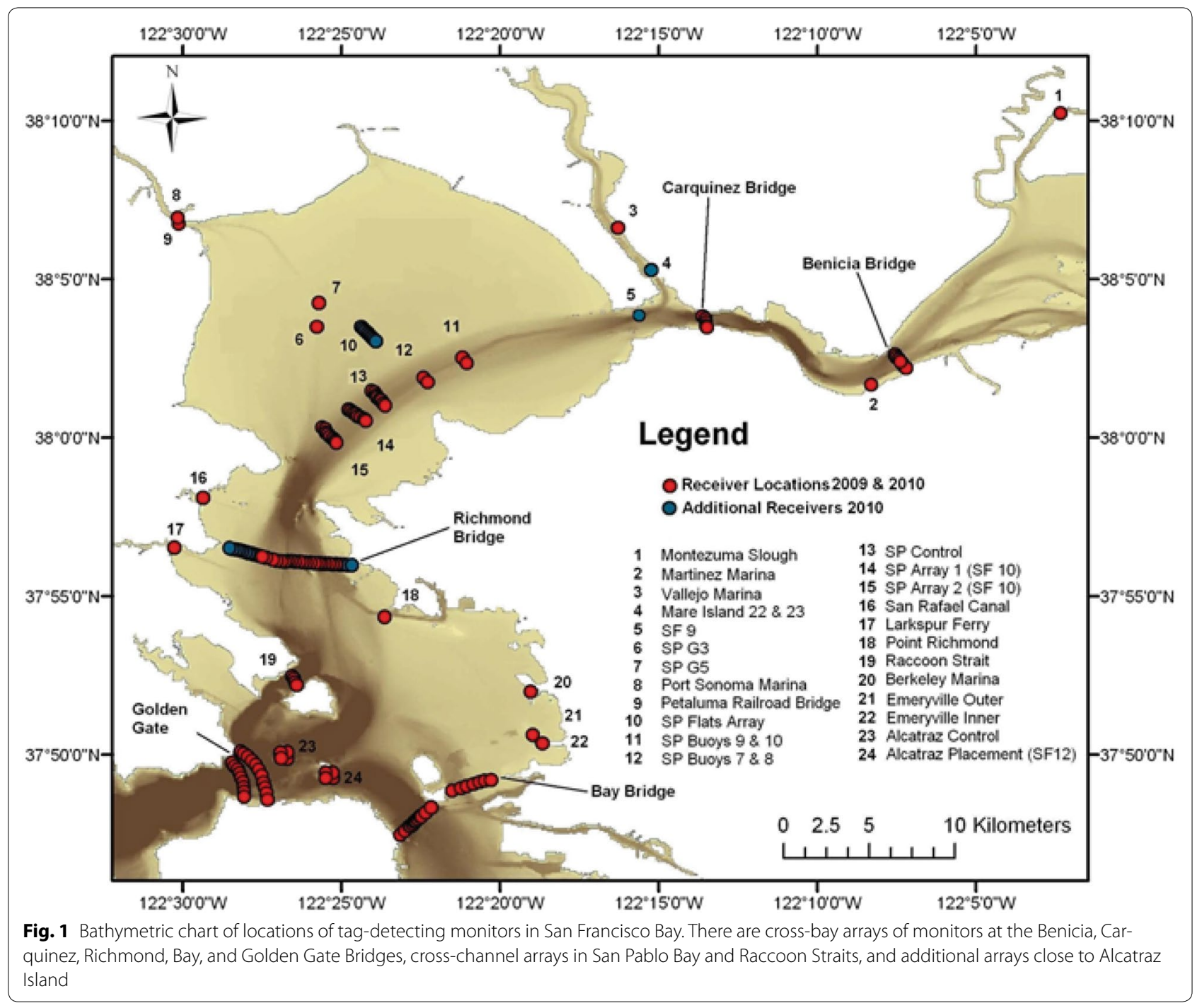


we refrained from trying to relate the swimming movements of the sharks to flows. This is being done based on actively tracking individual sharks by a vessel, over multiple tidal cycles, and relating the movements observed to flows predicted using a tidal model (Buckhorn et al. in prep.). The tags were placed within the peritoneal cavity by performing a small incision, $2.5 \mathrm{~cm}$ wide, in the ventral surface of the shark's body. The incision was closed with three sutures made of absorbable material. Handling time was kept under 7 min. All sharks were captured and released near Alcatraz Island (see Fig. 1).

An array of over 150 automated receivers (VR2W, Vemco Ltd., Halifax) deployed and managed by UC Davis and the National Marine Fisheries Service (californiafishtracking.ucdavis.edu/) was maintained in the San Francisco Estuary to detect coded transmitters on multiple species, including the sevengill shark. Whenever a tagged shark swam within a range, the receiver recorded the coded identity of the shark paired with a date and time of its passage. There were arrays of receiver deployed across the bay at the Benicia, Carquinez, San Rafael/Richmond, Bay, Golden Gate Bridges, and between Raccoon Island and Tiburon. There were two near Alcatraz Island. There were also cross-channel arrays of receivers in San Pablo Bay (SP) near disposal sites.

\section{Data analyses}

Files of detections of sevengill sharks were downloaded from the automated receivers and entered into the database maintained by members of the Biotelemetry Laboratory at the University of California, Davis. The database was queried for tag detections using MS Access, and the data were imported into MS for analysis. The tag data were displayed both in rectilinear and in circular plots and analyzed using circular statistics using software (Oriana 2.0). The Rayleigh test was used to determine the non-random concentration of detections in the temporal graphs [9].

We conducted an analysis of arrivals to identify any rhythmicity to arrival patterns during the diel cycle and throughout the 3 years of the study period (2008-2010). For this analysis, all time intervals of less than $15 \mathrm{~min}$ were considered part of a single visit, and intervals of $15 \mathrm{~min}$ or more were regarded as a different visit. Seasonal movements were also analyzed using a wave power analysis [10]. This decomposes a time series into time-frequency space to determine dominant modes of variability and their variation in time. The output of the wavelet analysis is the wavelet power spectrum, which is similar to the Fourier power spectrum. The global wavelet spectrum provides an unbiased estimation of the true power spectrum of a time series. We organized one-year datasets into daily detection bins and ran the analysis on the datasets separately for each location. The analysis was performed with the wavelet software (http://paos. colorado.edu/research/wavelets/software) in MATLAB (Mathworks Inc., Natick, MA).

The data are displayed in the following way. On the left is the wavelet power spectrum (WPS), which consists of the periods between detections plotted as a function of time of year. A random distribution of arrival intervals would exist outside of the black contours, which are regions of 95\% confidence interval level, and uncertainty exists if the color contours are below the dashed line that extends from the beginning of the period over which the shark was followed to its end. To the right of each WPS is the global wavelet spectrum (GWS), which indicates how the periods of detection, indicated by the solid line, differs from a random distribution, indicated by the dashed line.

\section{Results}

\section{Residency and site fidelity}

Twenty-one sevengill sharks were tagged near Alcatraz Island (Table 1). Many of these sharks exhibited seasonal and inter-annual site fidelity. Fifty-two percent of these sharks were detected repeatedly over a period of 3 months within SFB during 2008, 42\% were detected continuously for seven or more months during 2009, and $19 \%$ were detected persistently for six or more months during 2010. After being tagged during 2008, all 21 sharks were detected daily at the Golden Gate East (GGE) array for periods of half a month to six months (see gray triangles, Fig. 2). The same individuals were detected at Golden Gate East (GGE) on a daily basis during the same summer-fall periods during 2009 and 2010 (see Figs. 3, 4). Again, this pattern was exhibited by all sharks. For example, sharks remained a median of 45 and 47 days in 2008 at Golden Gate East (GGE) and Golden Gate West (GGW), respectively, 62 and 66 days in 2009 at GGE and GGW, and 68.5 and 71 days in 2010. The median number of days at Alcatraz Control was 2 in 2008, 26 in 2009, and 33 in 2010. The sharks visited other locations less than ten days during 2008-2010, except San Pablo Shipping Channel with 22 days in 2009.

There was a difference in where the adult and juvenile sevengill sharks resided within the bay (Fig. 5). The five adult males swam mainly at the mouth of the bay. Note that the five adult male sharks, SG1-SG5, were detected with large fractions of visits ranging from 0.40 to 0.45 of the total detections at both GG East and West, and with small fractions ranging from 0.02 to 0.1 .3 at the nearby Alcatraz and Alcatraz Control sites. The adult males rarely ventured farther into the bay, with only 0.01 of the detections in the northern bay by monitors at Raccoon Straits and only $0.01-0.02$ of the detections at 
Table 1 Sevengill sharks tagged from July to November 2008 near Alcatraz Island

\begin{tabular}{|c|c|c|c|c|c|}
\hline No. & ID & Date of tagging & Total length $(\mathrm{cm})$ & $\operatorname{Sex}(M, F)$ & Adult (A), juvenile (J) \\
\hline 1 & SG1 & July 17, 2008 & 177 & M & A \\
\hline 2 & SG2 & July 18, 2008 & 236 & M & A \\
\hline 3 & SG3 & July 28, 2008 & 210 & M & A \\
\hline 4 & SG4 & August 12, 2008 & 188 & M & A \\
\hline 5 & SG5 & August 13, 2008 & 176 & M & A \\
\hline 6 & SG6 & September 8, 2008 & 102 & M & J \\
\hline 7 & SG7 & September 8, 2008 & 153 & M & J \\
\hline 8 & SG8 & September 8, 2008 & 135 & $F$ & J \\
\hline 9 & SG9 & October 8, 2008 & 159 & M & J \\
\hline 10 & SG10 & October 8, 2008 & 147 & M & J \\
\hline 11 & SG11 & October 8, 2008 & 140 & M & Ј \\
\hline 12 & SG12 & October 8, 2008 & 132 & $\mathrm{~F}$ & J \\
\hline 13 & SG13 & October 8, 2008 & 142 & $\mathrm{~F}$ & Ј \\
\hline 14 & SG14 & October 9, 2008 & 157 & M & J \\
\hline 15 & SG15 & October 9, 2008 & 127 & M & J \\
\hline 16 & SG16 & October 9, 2008 & 139 & M & J \\
\hline 17 & SG17 & October 9, 2008 & 89 & $\mathrm{~F}$ & J \\
\hline 18 & SG18 & October 9, 2008 & 148 & M & J \\
\hline 19 & SG19 & October 9, 2008 & 133 & $F$ & J \\
\hline 20 & SG20 & October 9, 2008 & 142 & M & 」 \\
\hline 21 & SG21 & November 8, 2008 & 293 & $\mathrm{~F}$ & $A$ \\
\hline
\end{tabular}

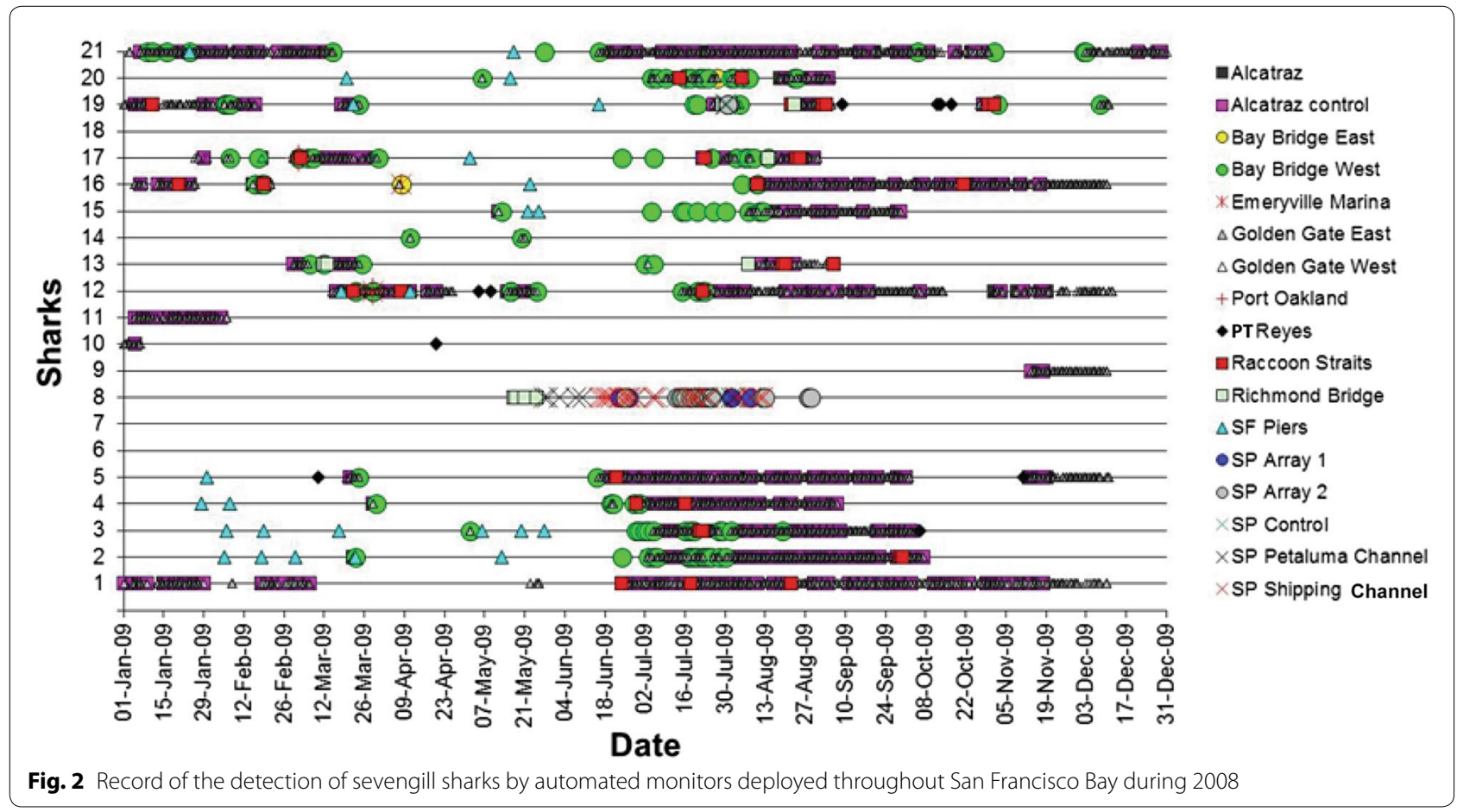

the Bay Bridge West and San Francisco Piers. Only one mature female was tagged. She behaved similarly to the adult males, staying 0.38 and 0.41 of the time at GGE and
GGW, 0.05 and 0.12 at the Alcatraz and Alcatraz Control sites, and only 0.20 in the southern bay at the Bay Bridge West. The juvenile males and females were also 



often detected near the GGE and GGW monitors, ranging from 0.20 to 0.50 of the time, and at the nearby Alcatraz sites. However, they also resided farther within the estuary in San Pablo Bay and the South Bay. The juvenile females were detected from 0.20 to 0.17 of the time at the SP array and the SP control north of the Richmond 


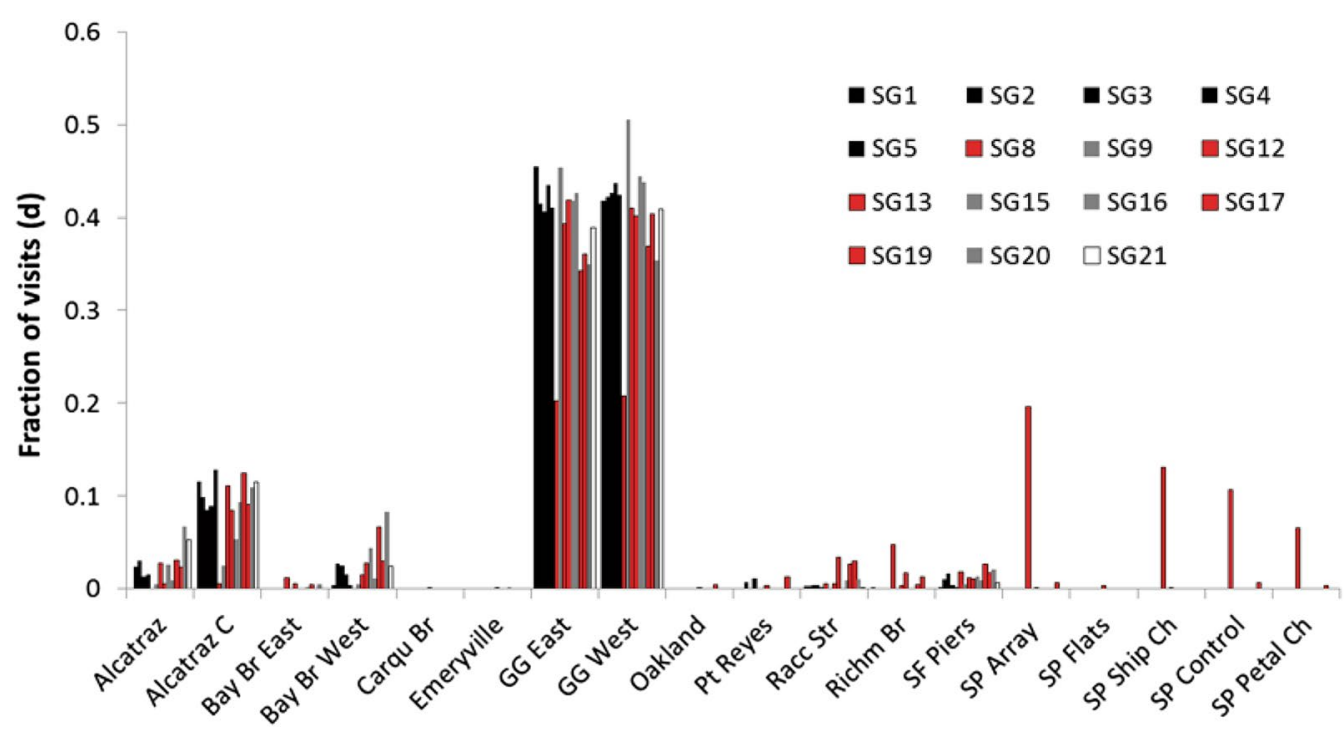

Fig. 5 Site preferences of sevengill sharks of different age and sex. There were five adult males (black squares), one adult female (clear square), four juvenile males (gray squares), and five juvenile females (red squares) recorded at sites throughout San Francisco Bay

Bridge, 0.05 by the monitors in the channel leading to the Petaluma River, and 0.12 as far within the northern bay as the Ship Channel.

\section{Diel and seasonal movement}

The sevengill sharks moved into the range of the receivers at the Golden Gate both during daytime and nighttime without a strong preference for a particular time of the day. The percentage of detections at this site is presented in circular graphs with midnight at the top and noon at the bottom. It is apparent in the circular graph for GG East, where the greatest number of detections were recorded, that sharks were detected at all times of the day (upper left in Fig. 6). There were more detections soon after midnight and at 6:00 a.m., but these differences were not statistically significant. This is evident from the small $\mathrm{r}$ vector calculated for detections over one full year of $0.275 \pm 0.026$ at GGE. This pattern existed over a period of 3 years (Fig. 7). On the other hand, sharks had a strong preference for daytime hours at most other locations in SFB. For example, at the Bay Bridge they arrived at a median time of $8: 18 \mathrm{~h}$ with a large $\mathrm{r}$ value of $0.612 \pm 0.08$ (lower left) and at San Pablo Bay (upper right) with a median arrival time of $11: 32 \mathrm{~h}$ with a large $r$ vector of $0.768 \pm 0.07$. In contrast, at Point Reyes sharks had a strong preference for nighttime with a median arrival of $3: 48 \mathrm{~h}$ indicated by a very large $\mathrm{r}$ vector of $0.999 \pm 0.08$ (lower right).

Sevengills moved to and from SFB with different periodicities. We present graphs of the power spectra for Golden Gate West and Point Reyes. One can identify particular periodicities from each graph. At the Golden Gate West, there was a recurrent interval of 16 days in the spring and fall as evident from the dark red areas enclosed in dark black lines during April and September 2009 on the graph to the left and the peak in the solid line passing to the left of the dashed line at a period of 16 days (top in Fig. 8). There was also a longer recurrent period of 256 days as evident by the broad dark red peak toward the bottom of the graph to the left and the peak in the solid line to the right of the dashed line indicating a random distribution of periodicities. At Point Reyes, arrivals occurred with a periodicity of 4 days evident by the dark red areas enclosed by black lines on the graph to the right during April and October and the peak in the solid line in the graph to the left that extends to the right of the dashed line (bottom in Fig. 8).

\section{Migration}

The sevengill sharks do make long-distance migrations. Three sevengill sharks (SG5, SG16, SG20) were detected by a receivers maintained by Scripps Institution of Oceanography off San Diego County, California, roughly $800 \mathrm{~km}$ southeastward along the coastline from San Francisco Bay. One mature male sevengill (SG-05) exhibited a 'ping-pong' pattern of migration between central and southern California. After its last detection in SFB on December 15, 2009, SG5 was detected by autonomous receivers deployed in 4-9-m-depth off La Jolla sporadically from January 30, 2010 to March 5, 2012, mostly during nighttime. This shark ventured southward $40 \mathrm{~km}$ to the mouth of the Tijuana River, $2 \mathrm{~km}$ north of the 

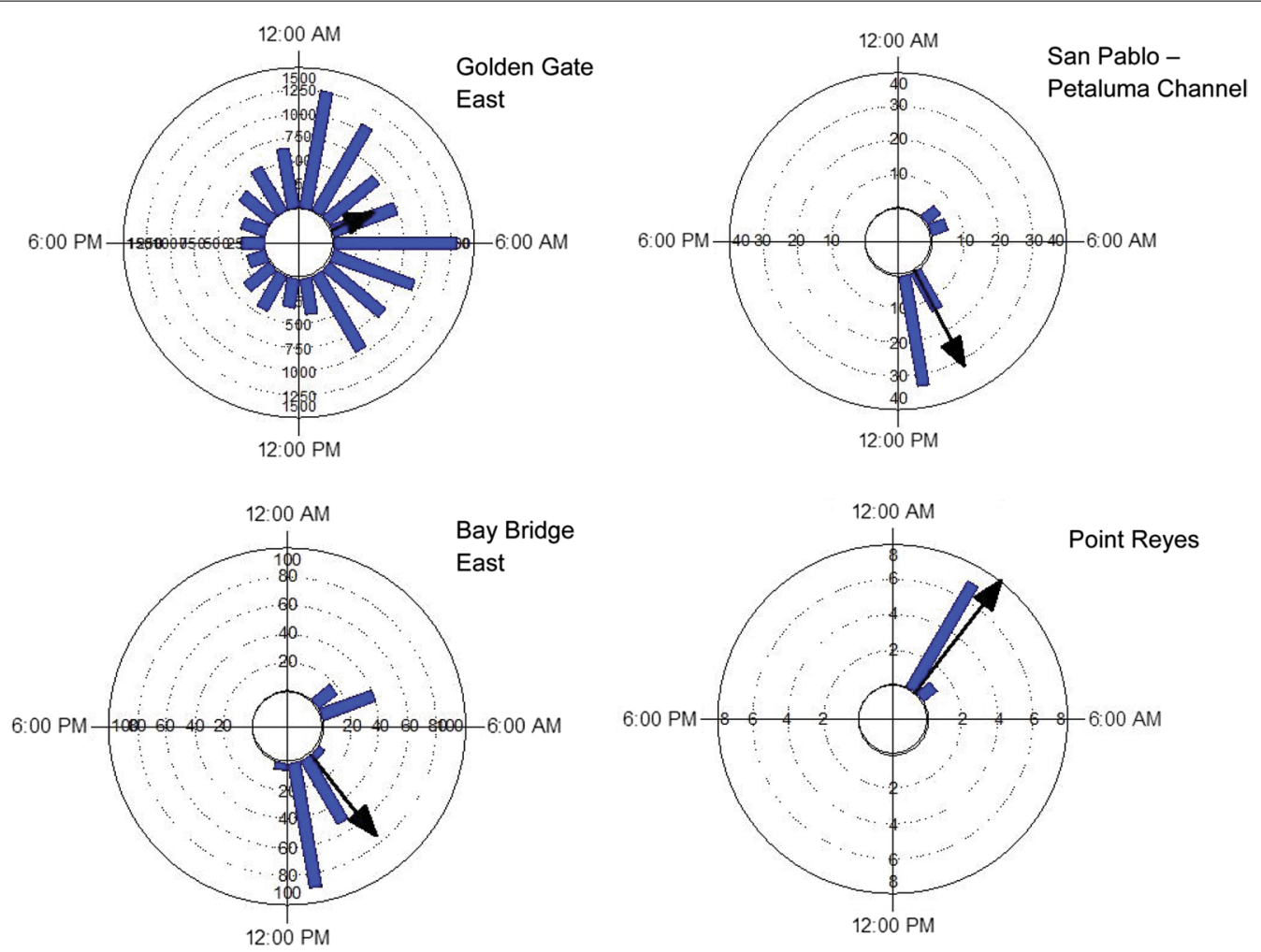

Fig. 6 Time of day that sevengill sharks were detected by monitors at four locations within San Francisco Bay. The histogram bars indicate the number of detections during a particular time of day. The black arrow indicates the degree of concentration at a particular time-the longer the array the greater the concentration of detections at a particular time

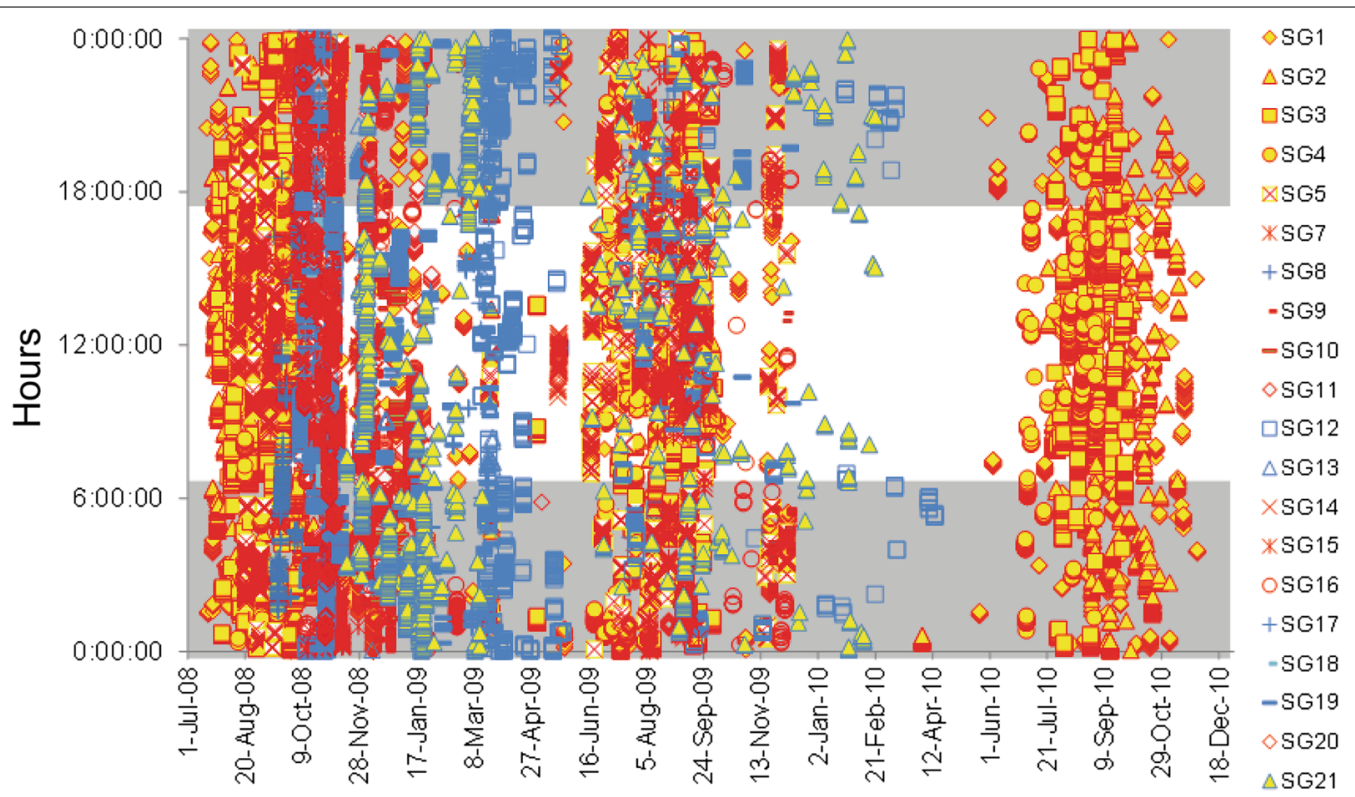

Date

Fig. 7 Detections of sevengill sharks over 24-h diel cycles by the receiver identified as Golden Gate West from July 1, 2008 to December 18, 2010 


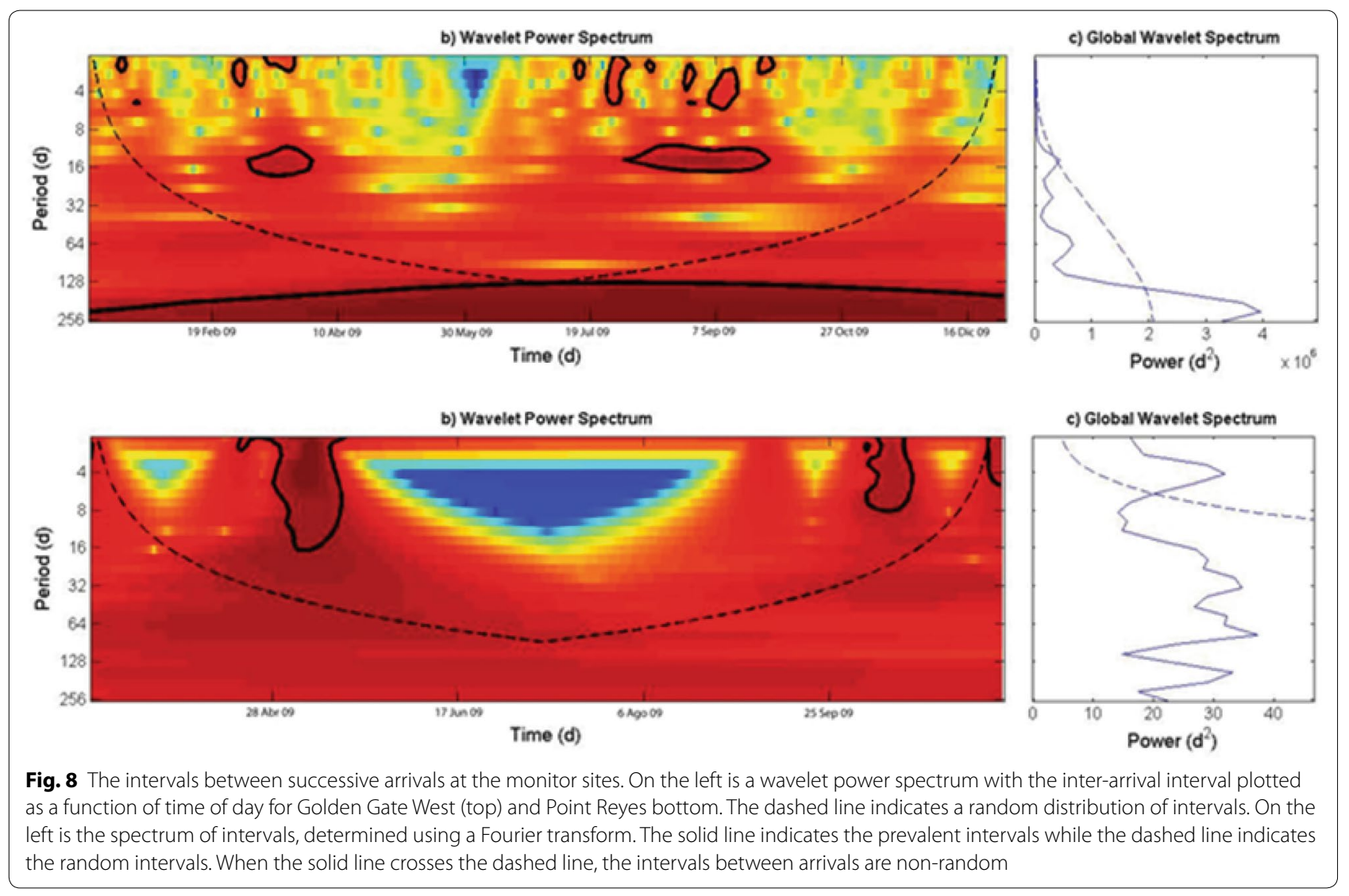

Mexican border, on November 8 and 9, 2011. It returned to SFB on October 19, 2012 and stayed until November 16,2012 , roughly a month before returning to La Jolla December 25, 2012, and was detected twice more on February 27 and March 2, 2013. After its last detection in SFB on December 15, 2009, SG16 was detected off La Jolla on January 1, 2010, traveling some $800 \mathrm{~km}$, roughly $57 \mathrm{~km}$ per day, in only 2 weeks. This shark was also detected near the mouth of the Tijuana River on March 12 and 27, 2010. Lastly, SG20 was detected off La Jolla on November 18, 2009, after being last detected in SFB on September 10, 2009.

\section{Discussion}

Twenty-one sevengill sharks were outfitted with individually coded ultrasonic beacons, and presence within the bay at various locations was determined over a period of three years by tag-detecting monitors deployed throughout the bay. There was strong evidence of inter-annual residency of sharks within SFB, and individuals repeatedly returned to the same regions of the bay. Inter-annual residency has been shown for the scalloped hammerhead sharks at seamounts [11] and islands [12], and individuals have been demonstrated to stay in confined areas at a seamount [13] and island [14]. White sharks, identified based on unique notches in their fins or coded ultrasonic beacons, have been observed to return from September to December to Southeastern Farallon Island over multiple years [15-17], and to feed at particular sites around the island 15.

Despite the high level of residency exhibited by sevengill sharks in San Francisco Bay, some showed fairly extensive north-south migrations as evidenced by detections of three sevengills by acoustic receivers along San Diego County. Two of these sharks were detected as far south as the mouth of the Tijuana River and likely entered Mexican waters at least occasionally. Unfortunately, acoustic receivers were not in operation along the Mexican coast during these times to confirm their movements extend out of US waters. However, if they do enter Mexico, it will be necessary to manage this species at the international level. Future work should track the movements of sevengills tagged in southern California and extend the existing array of acoustic receivers southward into Mexico.

\section{Authors' contributions}

MB and CTS tagged the sevengill sharks. JK downloaded the files of tag detections and analyzed them as well as wrote the manuscript. APK obtained funding for the project, planned the study, and helped during the analysis of the data and writing of the manuscript. All authors read and approved the final manuscript. 


\section{Author details}

${ }^{1}$ Biotelemetry Laboratory, Department of Wildlife, Fish, and Conservation Biology, University of California, One Shields Avenue, Davis, CA 95616, USA.

${ }^{2}$ Aquarium of the Bay, The Bay Institute, The Embarcadero at Beach Street, San Francisco, CA 94133, USA. ${ }^{3}$ Department of Environmental and Ocean Sciences, University of San Diego, 5998 Acala Park, San Diego, CA 92110, USA.

${ }^{4}$ Present Address: Biotelemetry Consultants, 2870 Eastman Lane, Petaluma, CA 94952, USA.

\section{Acknowledgements}

The authors would like to thank the members of the Biotelemetry Laboratory, who downloaded the monitors in San Francisco Bay on a trimester schedule. They want to acknowledge the assistance of Michael McGill, who served as skipper of the Aquarium of the Bay's collecting vessel when tagging sharks. Finally, we would like to thank the Aquarium of the Bay for providing funding for the study through their Foundation. The Aquarium of the Bay/Bay Institute also paid the cost of publication in Journal of Animal Biotelemetry.

\section{Competing interests}

The authors declare that they have no completing interests.

\section{Publisher's Note}

Springer Nature remains neutral with regard to jurisdictional claims in published maps and institutional affiliations.

Received: 24 July 2016 Accepted: 19 November 2017

Published online: 04 December 2017

\section{References}

1. Hearn AR, Chapman ED, Singer GP, Brostoff WN, LaCivita PE, Klimley AP. Movements of out-migrating late-fall run Chinook salmon (Oncorhynchus tshawytscha) smolts through the San Francisco Bay Estuary. Environ Biol Fish. 2014;97:851-63.

2. Chapman ED, Hearn AR, Singer GP, Brostoff WN, LaCivita PE, Klimley AP. Movements of out-migrating steelhead smolts through the San Francisco Bay Estuary. Environ Biol Fish. 2014. https://doi.org/10.1007/ s10641-014-0341-9.

3. Kelly JT, Klimley AP, Crocker CE. Movements of green sturgeon, Acipenser mediostris, in the San Francisco Estuary, California. Environ Biol Fish. 2007;29:281-95.
4. Heupel MR, Simpfendorfer CA. Movement and distribution of young bull sharks Carcharhinus leucas in a variable estuarine environment. Aquat Biol. 2008;1:277-89.

5. Curtis TH, Pakyn DC, Burgess GH. Use of human-altered habitats by bull sharks in a Florida nursery area. Mar Coast Fish. 2013;5:28-38.

6. Klimley AP. The biology of sharks and rays. Chicago: University of Chicago Press; 2013.

7. Ebert DA. Sharks, rays, and chimaeras of California. Berkeley: UC Press; 2003.

8. Compagno L, Dando M, Fowler S. Sharks of the world. Princeton: Princeton Press; 2005

9. Batschelet E. Circular statistics in biology. London: Academic Press; 1981.

10. Torrence C, Compo GP. A practical guide to wavelet analysis. Bull Am Meteorol Soc. 1998;79:61-78.

11. Klimley AP. Social organization of schools of scalloped hammerhead shark, Sphyrna lewini (Griffith and Smith), in the Gulf of California. San Diego: University of California; 1982.

12. Ketchum JT, Hearn A, Klimley AP, Peñaherrera C, Espinosa E, Bessudo S, Soler G, Arauz R. Inter-island movements of scalloped hammerhead sharks (Sphyrna lewini) and seasonal connectivity in a marine protected area of the eastern tropical Pacific. Mar Biol. 2014;16:939-51.

13. Klimley AP, Butler SB, Nelson DR, Stull AT. Diel movements of scalloped hammerhead sharks (Sphyrna lewini Griffith and Smith) to and from a seamount in the Gulf of California. J Fish Biol. 1988;33:751-61.

14. Hearn A, Ketchum J, Klimley AP. Hotspots within hotspots? Hammerhead shark movements at Wolf Island in Galapagos Marine Reserve. Mar Biol. 2010;157:1899-915.

15. Klimley AP, Anderson SD. Residency patterns of white sharks at the South Farallon Islands, California. In: Klimley AP, Ainley DG, editors. Great white sharks: the biology of carcharodon carcharias. San Diego: Academic Press; 1996. p. 365-73.

16. Jorgensen SJ, Reeb CA, Chapple TK, Anderson S, Perle C, Van Sommeran SR, Fritz-Cope C, Brown AC, Klimley AP, Block BA. Fidelity, homing and population structure revealed using electronic and genetic tag in white sharks of the Eastern Pacific. Proc R Soc B. 2009;1155:1-11.

17. Anderson SD, Chapple TK, Jorgensen SJ, Klimley AP, Block BA. Long-term individual identification and site fidelity of great white sharks, Carcharodon carcharias, off California using dorsal fins. Mar Biol. 2011;158:1233-7.

\section{Submit your next manuscript to BioMed Central and we will help you at every step:}

- We accept pre-submission inquiries

- Our selector tool helps you to find the most relevant journal

- We provide round the clock customer support

- Convenient online submission

- Thorough peer review

- Inclusion in PubMed and all major indexing services

- Maximum visibility for your research

Submit your manuscript at www.biomedcentral com/submit
BioMed Central 